\title{
A Review of Progress in Soundscapes and an Approach to Soundscape Planning
}

\author{
A. Lex Brown
}

Urban Research Program, Griffith School of Environment, Griffith University, Nathan, 4111, Brisbane, Australia

(Received August 16, 2011, Accepted December 12, 2011)

The soundscape approach considers the acoustic environment as a resource, focusing on sounds people want or prefer. Quiet is not a core requirement for such acoustic preference in the outdoor acoustic environment. Core requirements include congruent soundscape and landscape, and dominant wanted sounds in a place over, and not masked by, unwanted sounds. Acceptance, and further development, of the soundscape approach is facilitated by distinguishing it, both conceptually and in measurement and management approaches, from environmental noise management. Soundscape design, planning, and management, based on soundscape concepts, augment environmental noise management approaches, expanding the scope of application of the tools of acoustic specialists.

\section{INTRODUCTION}

The term soundscape, in the couple of decades since popularised by Schafer ${ }^{1}$ and others, has had a range of applications. It has encompassed the recordings of the sounds of nature; compositions based on, or of, natural sounds; studies of the sounds heard in villages and rural environments; analysis of the way acoustic environments have been described in history and in literature; analysis and description of all types of acoustic environments; and the creation of artistic sound installations. $^{2}$

While cognizant of these different applications of the term, this paper has a specific focus on soundscapes as applied to the management, planning, and design of the acoustic environment - primarily, but not exclusively, the acoustic environment of outdoor space. The established field of environmental noise management also deals with the acoustic environment of outdoor space, and clearly there are linkages and necessary distinctions between the two approaches, and these will be discussed further below. A current tendency towards a devaluation of the term soundscape by its use as a synonym for community noise would best be avoided. A community noise survey, for example, is not a soundscape survey; nor is a map of urban noise a soundscape map.

The field of soundscapes intersects, to various degrees, with fields of acoustics such as sound quality, human acoustic comfort in buildings, and music - and also with nonacoustic fields such as wilderness and recreation management, urban and housing design, and landscape planning and management. Soundscapes involve diverse fields of practice, approaches, and disciplinary interests (see, for examples, reviews by Hiramatsu of soundscape studies in Japan ${ }^{3}$ and Lercher and Schulte-Fortkamp. ${ }^{4}$

\section{SOUNDSCAPE IS PERCEPTION OF THE ACOUSTIC ENVIRONMENT OF A PLACE}

Central to the term soundscape is an individual's, or society's, perception and understanding of the acoustic en- vironment. $^{5-12}$ Thus, a soundscape exists through human perception-but always within the context of a particular time, place, and activity. The acoustic environment as perceived and understood, by people, in context, is a definition of soundscape that may be adopted in a future acoustic standard. ${ }^{13}$ This perceptual construct of the soundscape allows it to be applied, not just to a place as it is experienced, but also to a place in memory ${ }^{14}$ or even to abstract constructions such as musical compositions ${ }^{2}$ or sound installations. Herranz-Pascaul et al. ${ }^{15}$ provide a good theoretical person-place-activity modelfirmly rooted in the psychological process of environmental experience - through which to understand and research soundscapes.

Various authors have drawn the useful analogy of soundscape as the auditory equivalent of landscape. ${ }^{1,7,11,14,16,17}$ The European Landscape Convention Agreements ${ }^{18}$ define landscape as "an area, as perceived by people, whose character is the result of the action and interaction of natural and/or human factors". This is a good basis for an analogous soundscape definition. Substituting place for area because of the high spatial variability of the acoustic environment over any area, a useful definition of soundscape is obtained: soundscape is the acoustic environment of a place, as perceived by people, whose character is the result of the action and interaction of natural and/or human factors. The Convention goes on to define landscape policy, landscape planning, and landscape management. Again by analogy, this usefully leads to the definition of soundscape policy as the expression by the competent public authorities of general principles, strategies, and guidelines aimed at the protection, management, and planning of soundscapes - and similarly to soundscape management and soundscape planning.

While the soundscape of a place is thus a perceived entity, soundscape management, soundscape planning, or soundscape design aim at management or manipulation of the acoustic environment of a place to change the way that its acoustic environment is perceived by humans. The soundscape is perceived in a physical, often outdoor area/space/location, and that place also has certain visual and other properties associated with its 